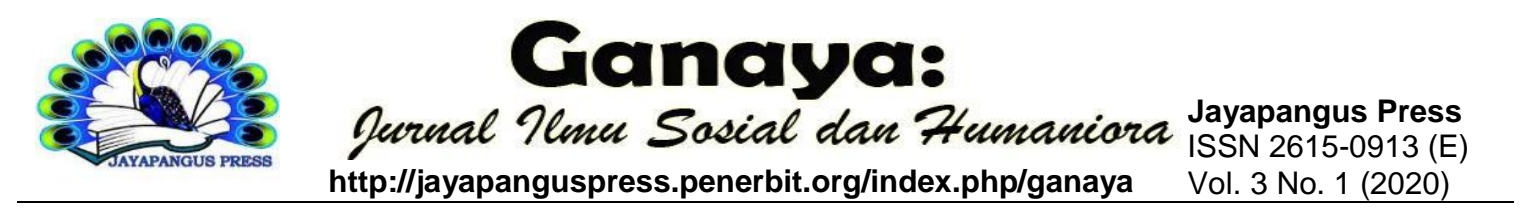

\title{
Tranformasi Manajemen Universitas menggunakan Framework Cobit 5 di Era Industri 4.0
}

\section{Oleh}

Seri Hartati ${ }^{1}$, Amir Syamsuadi $^{2}$, Luluk Elvitaria ${ }^{3}$

${ }^{1,2}$ Program Studi Ilmu Pemerintahan, Fakultas Ilmu Sosial dan Politik, Universitas

Abdurrab, Pekanbaru, Riau.

${ }^{3}$ Program Studi Teknik Informatika, Fakultas Teknik, Universitas Abdurrab, Pekanbaru, Riau.

${ }^{1}$ seri.hartati@univrab.ac.id

\begin{tabular}{l}
\hline Keywords: \\
\hline Education, \\
Framework Cobit \\
5, Industrial \\
Revolution, \\
Transformation, \\
Universitiy \\
\hline
\end{tabular}

Kata kunci:

Framework Cobit 5, Pendidikan, Revolusi Industri, Transformasi, Universitas

\begin{abstract}
The Industrial Revolution 4.0 has brought the consequences of increasing demands for accountability, transparency for all organization. This is made about a change in the organizational design paradigm. In this RI 4.0, adactive power and fast responsive are the key to success achieving the organization's vision and mission. . It is a challenge for universities to adjust various problems in this era of disruption. The transformation of educational organizations is one of alternative in order to realize that is oriented to public services and to prepare competent human resources in their fields. This research offers a solution for universities to find out how far the university is prepared to face this era. The research used a descriptive method with a qualitative approach. By using purposive sampling and determined data source by snowball, the results showed that the transformation of universities in Riau had to immediately adapt of demands in RI 4.0. The IT management level process showed that it was still in level 2, which is the managed process level. These processes were still at level 1 and level 2 so they need to be increased to a minimum at level 3 (Established). It is recommended to improve the management of IT services and the application of information security management become more effective, increasing the adaptive power of the industrial revolution 4.0
\end{abstract}

\begin{tabular}{|c|}
\hline Abstrak \\
\hline $\begin{array}{l}\text { Perkembangan era Revolusi Industri } 4.0 \text { yang membawa } \\
\text { konsekuensi meningkatnya tuntutan akuntabilitas dan } \\
\text { transparansi dari organisasi pendidikan serta responsif yang } \\
\text { tinggi dan cepat, hal ini membawa perubahan paradigma desain } \\
\text { organisasi. Pada era Revolusi Industri } 4.0 \text { daya adaktif lah yang } \\
\text { menjadi kunci keberhasilan meraih prestasi dan mencapai visi }\end{array}$ \\
\hline
\end{tabular}


dan misi organisasi. . Menjadi sebuah tantangan bagi universitas bagaimana menyesuaikan berbagai masalah dalam era disrupsi ini. Transformasi organisasi pendidikan merupakan salah satu alternatif yang dapat ditempuh dalam rangka mewujudkan organisasi yang berorientasi layanan publik dan mampu menyiapkan sumber daya manusia yang berkompeten di bidangnya. Penelitian ini menawarkan sebuah solusi bagi universitas untuk mencari tau sejauhmana kesiapan universitas menghadapi era tersebut. Adapun penelitian ini menggunakan metode deskriptif dengan pendekatan kualitatif. Pengambilan sampel atau sumber data pada penelitian ini dilakukan secara puposive dan untuk ukuran sampel tersebut ditentukan secara snowball. Menggunakan Framework Cobit 5 dapat digambarkan bagaimana kematangan manajemen TI sebuah isntitusi. Hasil Penelitian menunjukkan bahwa Transformasi universitasuniversitas yang ada di Riau harus segera beradaptasi dengan permintaan di era industri 4.0. Proses level manajemen TI menunjukkan masih dalam level 2 yaitu level managed proses. Proses-proses tersebut masih berada pada level 1 dan level 2 sehingga perlu ditingkatkan menjadi minimum berada pada level 3 (Established). Direkomendasikan agar universitas untuk memperbaiki pengelolaan layanan TI serta penerapan manajemen kemananan informasi yang lebih efektif.

\section{Pendahuluan}

Hari ini seluruh negara di dunia baru melihat efek dari Internet of Things (IOT). Perkembangan penggunaan internet dan teknologi digital sebagai tulang punggung pergerakan dan jaringan konektivitas manusia dan mesin. Hal ini akan berdampak berbagai aktivitas manusia untuk bidang IPTEK serta pendidikan tinggi (Meutia, 2017), (Sulistyanto, Nugraha, Sari, Karima, \& Asrori, 2015).

Revolusi Industri 4.0 sebagai perkembangan peradaban modern telah kita rasakan dampaknya pada berbagai sendi kehidupan, penetrasi teknologi yang serba disruptif, menjadikan perubahan semakin cepat, sebagai konsekuensi dari fenomena IoT, big data, otomasi, robotika, komputasi awan, hingga kecerdasan buatan (Fonna, 2019), (Sawitri, 2019). Tantangan terrbesar menghadapi revolusi Industri 4.0 adalah dalam menciptakan teknologi dan pendekatan baru yang menggabungkan dunia fisik dan digital. Gejala disrupsi yang mewarnai perkembangan peradaban Revolusi Industri 4.0, akan mengarahkan pada realita transisi revolusi teknologi yang secara fundamental akan mengubah cara hidup, bekerja, dan relasi organisasi dalam berhubungan satu sama lain (Savitri, 2019), (Ghufron, 2018). 
Perubahan lanskap ekonomi politik dan relasi organisasi sebagai konsekuensi Revolusi Industri Tata kelola untuk pendidikan tinggi . Perubahan dratis yang muncul akibat revolusi industri keempat tidak boleh diabaikan. Transformasi dalam bidang pendidikan ini semakin relevan untuk dipacu percepatannya bila kita merujuk pendapat Klaus Schwab, Executive Chairman World Economic Forum, yang memberikan hipotesa saat ini miliaran orang telah terhubung dengan perangkat mobile, penemuan kecepatan pemrosesan byte demi byte data internet, yang telah meningkatkan kapasitas pengetahuan manusia melebihi sistem konvensional (Rahadian, 2019).

Perkembangan era Revolusi Industri 4.0 yang membawa konsekuensi meningkatnya tuntutan akuntabilitas dan transparansi dari organisasi pendidikan serta responsif yang tinggi dan cepat, hal ini membawa perubahan paradigma desain organisasi (Mukodi, 2019). Pada era Revolusi Industri 4.0 daya adaptif lah yang menjadi kunci keberhasilan meraih prestasi dan mencapai visi dan misi organisasi (Puspitasari, 2018). Pada organisasi bisnis, fenomena ini dapat kita cermati dari fenomena Uber , Grab, GoCar yang mengancam pemain-pemain besar pada industri transportasi di seluruh dunia dan juga ada Traveloka yang merubah sistem pembelian tiket yang tadinya manual (Athoillah, Firdaus, \& Sanim, 2019). Bercermin dari survival organisasi bisnis sudah sepatutnya organisasi pemerintah dan organisasi pendidikan lebih peka dan melakukan penyesuaian, sehingga mampu bersaing di tengah perkembangan peradaban Revolusi Industri 4.0 guna tetap survive dalam menjalankan tugas pokok dan fungsinya dengan lebih efesien dan efektif sebagai responsit terhadap meningkatnya tuntutan akuntabilitas dan transparasi publik.

Pengembangan kelembagaan organisasi melalui transformasi yang terencana dan terukur, sangat dibutuhkan dalam menjawab problem statement yang menjadi ciri kelemahan organisasi pada umumnya, yang dipandang perlu meningkatkan responsivitas, transparansi, membangun sistem dan mekanisme yang accessible (Saggaf, Said, \& Saggaf, 2018). Menurut Prasetyo H, tren peningkatan jumlah riset tiap tahunnya menjadi bukti bahwa para akademisi mulai mengarahkan fokus risetnya pada Industri 4.0. Kondisi ini perlu diperhatikan oleh dunia pendidikan terutama di negara-negara berkembang agar segera tanggap terhadap perubahan yang terjadi dan mempersiapkan sumber daya yang dimiliki dalam rangka menghadapi tren Industri (Prasetyo \& Sutopo, 2018). 
Informasi merupakan sumber daya utama bagi enterprise. Teknologi memegang peranan penting yang dapat meningkatkan fungsi informasi pada enterprise, sosial, publik dan lingkungan bisnis. COBIT 5 memberikan layanan kerangka kerja secara komprehensif untuk membantu pemerintah dan manajemen IT dalam sebuah organisasi mencapai tujuan yang diharapkan .

Penelitian ini menawarkan transformasi manajemen sebuah universitas yang berdasarkan Kerangka kerja COBIT 5 digunakan untuk membangun model tata kelola TI di Pendidikan Tinggi memberikan panduan tentang bagaimana itu harus dikelola menyadari manfaat TI, optimalisasi sumber daya, dan pengoptimalan manajemen risiko. Penelitian ini menggunakan kerangka COBIT 5 menyediakan kerangka kerja yang komprehensif membantu organisasi dalam mencapai tujuan merekatata kelola dan manajemen TI (Djapandjatay, Tanaamah, \& Tanaem, 2018). Secara sederhana, ini membantu sebuah organisasi membuat optimal pengelolaan TI dengan menjaga keseimbangan antara menyadari manfaat dan mengoptimalkan tingkat risiko danpenggunaan sumber daya. COBIT 5 memungkinkan TI untuk diatur dan dikelola secara holistik untuk keseluruhan organisasi, mengambil dalam bisnis end-to-end penuh dan bidang fungsional tanggung jawab TI, mempertimbangkan kepentingan TI terkait internal dan pemangku kepentingan eksternal. COBIT 5 bersifat generik dan berguna untuk organisasi dari semua ukuran, apakah komersial, nirlaba atau di sektor publik (Umar, Riadi, \& Handoyo, 2019), (Ibrahim \& Nurpulaela, 2018).

\section{Metode}

Penelitian ini merupakan sebuah penelitian deskriptif dengan pendekatan kualitatif. Moloeng mendefinisikan penelitian kualitatif sebagai prosedur penelitian yang menghasilkan data deskriptif berupa kata-kata tertulis atau lisan dari orang-orang dan perilaku yang diamati dari fenomena yang terjadi. Lebih lanjut Moleong mengemukakan bahwa penelitian deskriptif menekankan pada data berupa kata-kata, gambar, dan bukan angka-angka yang disebabkan oleh adanya penerapan metode kualitatif. Selain itu, semua yang dikumpulkan berkemungkinan menjadi kunci terhadap apa yang sudah diteliti (Moleong, 2017). Pengambilan sampel atau sumber data pada penelitian ini dilakukan secara puposive dan untuk ukuran sampel tersebut ditentukan secara snowball, taknik pengumpulan dengan triangulasi (gabungan), analisa data bersifat kualitatif dan hasil penelitian menekankan makna generalisasi. 
Dalam penelitian ini digunakan pula metode Ordinal, teknik pengukuran ordinal ini dalam pembuatan kuisioner menggunakan skala likert. Ukuran ordinal digunakan dimana angka-angka tersebut mengandung pengertian tingkat level kematangan. Ukuran nominal digunakan untuk menentukan obyek dari tingkat paling rendah sampai ukuran paling tinggi. Kuisener yang dibuat diberi nomor $1=$ Tidak Setuju, $2=$ Ragu-Ragu, $3=$ Setuju, dan 4 = Sangat Setuju. Nilai absolut yang merupakan nilai model capability diberi nomor $0=$ Proses Tidak Lengkap, $1=$ Proses Dijalankan, $2=$ Proses Diatur, $3=$ Proses Tetap, 4 $=$ Proses Sudah di Ukur, 5 = Proses Optimasi. Penentuan nilai maturity dilakukan dengan cara melakukan perhitungan dalam bentuk indeks dengan rumus dibawah ini

$$
\text { Indeks }=\frac{\left.\sum \text { (Jawaban }\right)}{\sum(\text { Pertanyaan Kuisioner })}
$$

Kemudian untuk Standar tingkat kematangan yang dijadikan standar Model Maturity merujuk pada dokumen ISACA seperti pada tabel 3.2 Tingkat Maturity Model. Penentuan tingkat maturity menggunakan nilai real demi mempermudah dalam penghitungan dan proses perekomendasian seperti dapat terlihat dalam tabel.

Tabel 1. Maturity Level Framework Cobit 5

\begin{tabular}{|c|l|}
\hline Index & \multicolumn{1}{|c|}{ Tingkat Maturity Model } \\
\hline 0 & Incomplete Process (Proses Tidak Lengkap) \\
\hline 1 & Performed Process (Proses Dijalankan \\
\hline 2 & Managed Process (Proses Diatur) \\
\hline 3 & Established Process (Proses Tetap) \\
\hline 4 & Predictable Process (Proses Diukur) \\
\hline 5 & Optimising Process (Proses Optimasi) \\
\hline
\end{tabular}

Untuk menghasilkan perhitungan yang akurat dari hasil kuisener diperlukan nilai dalam bentuk bilangan bulat maka dilakukan skala pembulatan dengan contoh seperti pada tabel. Hasil pengelolaan data kuisioner dan wawancara dan dari hasil analisa yang diperoleh dilakukan pembuatan rekomendasi dari temuan untuk perbaikan instansi kedepannya merujuk pada tabel Skala Pembulatan indeks:

Tabel 2. Skala Pembulatan Indeks

\begin{tabular}{|l|c|}
\hline $\begin{array}{c}\text { Skala Pembulatan } \\
\text { Indeks }\end{array}$ & $\begin{array}{c}\text { Maturity } \\
\text { Level }\end{array}$ \\
\hline $0-0.25$ & 0 \\
\hline $0.26-1.26$ & 1 \\
\hline $1.27-2.77$ & 2 \\
\hline
\end{tabular}




\begin{tabular}{|l|l|}
\hline $2.78-4.28$ & 3 \\
\hline $4.29-5.79$ & 4 \\
\hline $5.8-7.3$ & 5 \\
\hline
\end{tabular}

Hasil dari penelitian ini mendeskripsikan atau mengkonstruksikan wawancarawawancara mendalam terhadap subjek penelitian sehingga dapat memberikan gambaran yang jelas dan transformasi yang di sarankan. Subjek penelitian ini adalah 6 perguruan tinggi yang ada di pekanbaru dengan responden berjumlah 20 orang. Metode kuesioner dilakukan dengan pembuatan kuesioner berdasarkan standar pada DSS05 Framework COBIT 5 dengan megkombinasiakan dengan capability level pada standar CMMI sehingga didapatkan bentuk kuesioner yang mampu menjawab kebutuhan pada keamanan sistem informasi yang ada di instansi tersebut. Butir pertanyaan yang ditanyakan dalam wawancara dapat dilihat pada tabel 3 berikut:

Tabel 3. Item Pertanyaan Berdasarkan Framework Cobit 5

\begin{tabular}{|l|l|}
\hline No & \multicolumn{1}{|c|}{ PERTANYAAN } \\
\hline 1. Evaluate, Direct, and Monitoring (EDM) 03 \\
\hline 1 & Universitas mampu memprediksi resiko secara optimal \\
\hline 2 & Universitas mampu melakukan perawatan IT \\
\hline 3 & Universitas mampu menangani resiko kerusakan perangkat IT yang terjadi \\
\hline $\mathbf{2 .}$ Evaluate, Direct, and Monitoring (EDM) 04 \\
\hline 1 & Universitas mampu mensosialisasikan system berkala \\
\hline 2 & Universitas mampu mengelola data dan keamanan data \\
\hline 3 & $\begin{array}{l}\text { Universitas mampu mengikuti pegawai untuk melakukan } \\
\text { pelatihan sesuai dengan bidangnya masing-masing }\end{array}$ \\
\hline 3. Align, Plan, and Organise (APO) 01 \\
\hline 1 & $\begin{array}{l}\text { Universitas mampu membuat kerangka kerja mencakupstruktur proses IT } \\
\text { dan hubungannya agar tidak terjadinya tumpang tindih }\end{array}$ \\
\hline 2 & $\begin{array}{l}\text { Universitas telah mampu mengukur kinerja, perbaikan, kepatuhan dan target } \\
\text { kualitas }\end{array}$ \\
\hline 3 & Universitas secara berkala berhak meninjau kinerja struktur organisasi IT \\
\hline 4. Align, Plan, and Organise (APO) 02 \\
\hline 1 & Universitas mampu mengerti strategi IT \\
\hline 2 & $\begin{array}{l}\text { Universitas telah mampu mengukur kinerja, perbaikan dan menganalisa data } \\
\text { teknologi dalam menyusun strategi dan target kualitas }\end{array}$ \\
\hline 3 & $\begin{array}{l}\text { Universitas mampu menganggulangi aspek darurat dalam } \\
\text { komponen infrastruktur }\end{array}$ \\
\hline
\end{tabular}




\begin{tabular}{|l|l|}
\hline \multicolumn{2}{|l|}{ 5. Align, Plan, and Organise (APO) 06 } \\
\hline 1 & Universitas mampu memanfaatkan TI untuk menghemat biaya \\
\hline 2 & Universitas mampu meningkatkan kinerja pegawai \\
\hline 3 & Universitas mengoptimasi pengadaan TI yang optimal \\
\hline 6. Align, Plan, and Organise (APO) 07 \\
\hline 1 & $\begin{array}{l}\text { Universitas telah secara teratur memverifikasi bahwa } \\
\text { personel memiliki kompetensi yang memenuhi peran } \\
\text { berdasarkan pelatihan atau pengalaman yang dimiliki staff TI }\end{array}$ \\
\hline 2 & Evaluasi tepat waktu telah dilakukan secara teratur sesuai tujuan individu \\
\hline 3 & Universitas melakukan mentoring kepada SDM \\
\hline 7. Deliver, Service, and, Support (DSS) 01 \\
\hline 1 & Rencana strategi didiskusikan dalam kerjasama dengan stakeholder terkait \\
\hline 2 & TI memberikan kontribusi untuk tujuan strategis Universitas \\
\hline 3 & Rencana strategis TI mencakup operasional anggaran \\
\hline 8. Deliver, Service, and, Support (DSS) 03 \\
\hline 1 & $\begin{array}{l}\text { Universitas mendefinisikan dan menetapkan peran penting } \\
\text { untuk mengelola resiko TI }\end{array}$ \\
\hline 2 & Universitas bertanggung jawab atas resiko yang berhubungan dengan TI \\
\hline 3 & Setiap personil memiliki tanggungjawab untuk memenuhi kebutuhan organisasi \\
\hline 9. Monitor, Evaluate, and Asses (MEA) 01 \\
\hline 1 & Universitas meninjau laporan untuk tujuan meningkatkan kontribusi TI \\
\hline 2 & Universitas menilai kerangka kerja secara keseluruhan kebijakan lingkungan \\
\hline 3 & Universitas mengembangkan dan mengevaluasi perangkat kebijakan \\
\hline
\end{tabular}

\section{Hasil dan Pembahasan}

\section{Hasil Penelitian}

Penggunaan sistem infromasi menjadi sangat penting dalam kemajuan universitas menghadapi persaingan global. Lembaga pendidikan tinggi yang bagus harus memiliki sistem informasi manajemen pendidikan yang cukup baik agar memberikan pelayanan prima kepada seluruh civitas akademika (mahasiswa, tenaga pengajar, pengelola) maupun pemangku kepentingan lainnya di luar lembaga Perguruan Tinggi itu sendiri. Di era industri 4.0 membangun tata kelola perguruan tinggi sangatlah penting dilakukan, baik dari sisi transparansi, akuntabilitas, tanggung jawab, berintegritas dan berkualitas. Untuk mewujudkan sebuah kampus yang ideal dengan pengelolaan yang baik, maka selain memiliki infrastruktur yang memadai, sarana dan prasarana, dan yang lebih penting adalah sumber daya manusia yang berkompetensi dibidangnya.

Permasalahan yang terjadi di beberapa perguruan tinggi adalah belum adanya suatu sistem tata kelola terstandar dalam pengelolaan TI, sehingga ditemukan penanganan permasalahan pada setiap pengguna dan masih belum adannya sistem integrasi pengelolaan data secara keseluruhan. Meningkatnya pengembangan sistem Informasi yangterus meningkat di kemudian hari mengakibatkan manajemen universitas harus 
adaptable terhadap permintaan di lapangan. Pengawasan maupun penilaian terhadap kinerja TI khususnya sistem informasi yang digunakan dan evaluasi kinerja dalam sistem informasi universitas tersebut belum dilakukan secara optimal. Untuk dapat mewujudkan visi dan misi universitas, maka diperlukan evaluasi/analisis dalam pengelolaan TI di universitas dengan menggnakan Framework COBIT 5. Dalam memetakan ke tingkat kematangan tertentu, Cobit 5 dapat memberikan informasi tentang kondisi TI universitas pada saat ini, sehingga diperlukan inovasi dalam mengembangkan sistem teknologi informasi dengan cepat dan akurat.

Berhasilnya tata kelola universitas saat ini ditentukan pada tata kelola dari Teknologi Informasi (TI) dikelola dengan baik. Penerapan TI ini berjalan dengan baik apabila ditunjang dengan suatu tata kelola TI yang baik pula. Universitas di riau dalam pengelolaannya serign menghadapi berbagai permasalahan terkait Sistem Informasi. Permasalahan pada sistem informasi universitas merupakan urgensi karena berkaitan dengan penyediaan layanan terhadap seluruh civitas akademika. Walaupun telah terdapat alur atau proses dalam pengelolaan permasalahan yang muncul pada sistem informasi, dalam penyelesaian permasalahan-permasalahan tersebut masih perlu. Jangka waktu penyelesaian masalah juga dinilai kurang cepat oleh pengguna. Dalam COBIT 5 dibagi dalam 5 domain utama yaitu, Seperti pada Gambar 1.

a. EDM adalah proses evaluasi, kelangsungan, dan monitoring.

b. APO adalah proses mensejajarkan, merencanakan dan mengatur.

c. BAI adalah proses membangun, mendapatkan, dan menerapkan.

d. DSS adalah proses mengirim, melayani dan dukungan.

e. MEA adalah proses memantau, evaluasi, dan menilai.

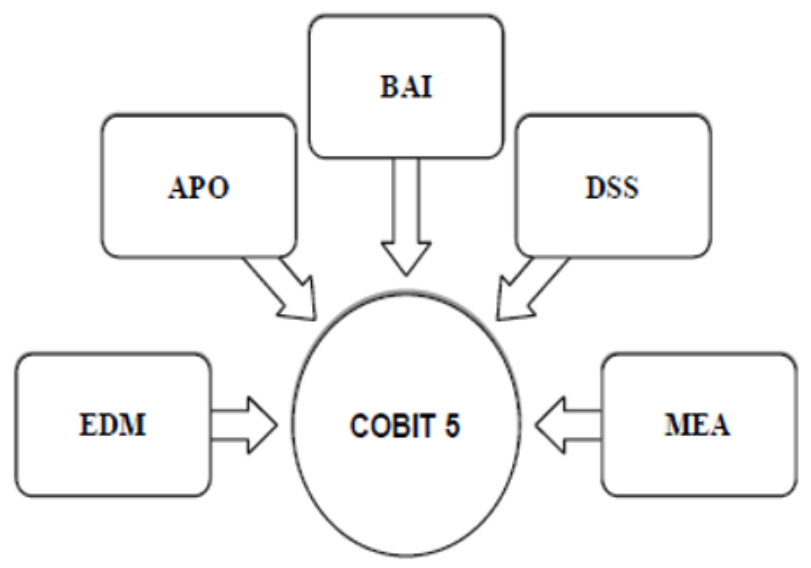

Gambar 1. Domain Cobit 5 
Berikut ini adalah tabel hasil skor penilaian untuk kerangka kerja Framework cobit 5 di Universitas - Universitas untuk wilayah kota Pekanbaru yang telah diteliti:

Tabel 3. Hasil Skor Penilaian

\begin{tabular}{|c|c|c|}
\hline \multicolumn{2}{|r|}{$\begin{array}{l}\text { 1. Evaluate, Direct, and Monitoring } \\
\text { (EDM) } 03\end{array}$} & $\begin{array}{l}\text { 6. Align, Plan, and Organise (APO) } \\
07\end{array}$ \\
\hline 1 & 2.54 & 2.65 \\
\hline 2 & 2.40 & 2.56 \\
\hline 3 & 2.76 & 2.76 \\
\hline \multicolumn{2}{|r|}{$\begin{array}{l}\text { 2. Evaluate, Direct, and Monitoring } \\
\text { (EDM) } 04\end{array}$} & $\begin{array}{l}\text { 7. Deliver, Service, and, Support } \\
\text { (DSS) } 01\end{array}$ \\
\hline 1 & 2.65 & \begin{tabular}{l|l}
1 & 2.78 \\
\end{tabular} \\
\hline 2 & 2.78 & \begin{tabular}{|l|l|}
2 & 2.78 \\
\end{tabular} \\
\hline 3 & 2.65 & $3 \quad 2.76$ \\
\hline \multicolumn{2}{|r|}{ 3. Align, Plan, and Organise (APO) 01} & $\begin{array}{l}\text { 8. Deliver, Service, and, Support } \\
\text { (DSS) } 03\end{array}$ \\
\hline 1 & 2.57 & \begin{tabular}{l|l}
1 & 2.80 \\
\end{tabular} \\
\hline 2 & 2.65 & \begin{tabular}{|l|l}
2 & 2.76 \\
\end{tabular} \\
\hline 3 & 2.76 & $3 \quad 2.65$ \\
\hline \multicolumn{2}{|r|}{ 4. Align, Plan, and Organise (APO) 02} & $\begin{array}{l}\text { 9. Monitor, Evaluate, and } \\
\text { Asses (MEA) } 01\end{array}$ \\
\hline 1 & 2.87 & \begin{tabular}{l|l}
1 & 2.54 \\
\end{tabular} \\
\hline 2 & 2.47 & $2 \quad 2.67$ \\
\hline 3 & 2.75 & \begin{tabular}{|l|l|}
3 & 2.45 \\
\end{tabular} \\
\hline \multicolumn{2}{|r|}{ 5. Align, Plan, and Organise (APO) 06} & \\
\hline 1 & 2.67 & \\
\hline 2 & 2.76 & \\
\hline 3 & 2.82 & \\
\hline
\end{tabular}

\section{Pembahasan}

Dari hasil penelitian menunjukkan tingkat kematangan rata - rata seluruh universitas yang telah diuji bernilai 2.67 dapat di lihat dalam skala pembulatan indeks berada pada tingkat maturity model 2 (managed proses), artinya universitas di pekanbaru telah berada pada tingkat dan proses menjalankan tata kelola TI dengan baik, sudah memiliki rancangan dan ukuran, serta telah dikontrol dengan baik.

Dengan COBIT 5 selain untuk tata kelola dan manajemen universitas, juga merupakan kumpulan instrumen yang mendukung untuk menjembatani jarak (gap) antara kebutuhan yang dikendalikan (control requirments), masalah teknis (technical issues) dan resiko bisnis (business risk). Selain itu pada COBIT 5 dilakukan pemisahan yang sangat jelas antara area governance dengan area manajemen. Area governance terdiri dari Evaluate, Direct and Monitor (EDM). Sedangkan area manajemen terdiri dari domain 
Align, Plan and Organize (APO), domain Build, Acquire and Implement (BAI), domain Deliver, Service and Support (DSS), dan Domain Monitor, Evaluate and Assess (MEA).

Perlu dikembangkan lagi dengan cakupan yang lebih luas, tidak hanya pada unit kerja atau pengembangan sdm saja, namun proses teknologi informasi yang mendukung dan lebih spesifik terhadap detail yang dilaksanakan sesuai dengan management practice COBIT 5. Sehingga aturan lengkap untuk pengelolaan teknologi informasi pada universitas yang betul-betul mendukung dan berjalan sesuai visi, misi dan tujuan universitas. Para Pimpinan universitas diperlukan kesadaran yang tinggi tentang urgensi tata kelola teknologi informasi. Agar siap menghadapi banyak perubahan di era industri 4.0, seyogyanya universitas berada pada level predictable dan optimasi. Level ini sangat siap untuk memenuhi kebutuhan di era industri 4.0 sekaligus untuk keberlanjutan menghadapi respons besar perubahan. Universitas juga di tuntut untuk menyediakan sebuah platform agar siap berinovasi pada persaingan global.

\section{Kesimpulan}

Berdasarkan hasil penelitian menggunkan Framework Cobit 5 dari 6 universitas di Riau bahwa tingkat kesiapan kematangan TI pada level managed procces. TataKelola Manajemen TI di beberapa universitas tersebut sudah pada tahap baik namun pada cavabiity level perlu dilakukan beberapa treatment dalam prosses BAI dan DSS. Proses tersebut masih pada level 1 dan 2, untuk meningkatkan level tersebut diharapkan universitas pada pengelolaan layanan TI dapat meningkatkan support pada implementasi sistem. Kombinasi framework COBIT 5 dan CMMI mampu memberikan kontribusi level keamanan teknologi yang maksimal. COBIT 5 membantu menyediakan kerangka kerja mengukur kinerja sistem informasi dan sudah dijalankan dengan baik sesuai dengan ketentuan yang telah ditetapkan untuk mencapai hasil yang diharapkan. Beberapa hal yang harus menjadi concern selanjutnya oleh pihak manajemen universitas adalah pada aspek prosedur dan kebijakan, daya dukung sumber daya baik kompetensi SDM dan fasilitas dan tools untuk meningkatkan efektifitas tata kelola TI yang baik.

\section{Daftar Pustaka}

Athoillah, A. S., Firdaus, M., \& Sanim, B. (2019). Competititve strategy of taxi company in facing environmental changes. BISMA (Bisnis Dan Manajemen), 12(1), 66. https://doi.org/10.26740/bisma.v12n1.p66-87 
Djapandjatay, J. R., Tanaamah, A. R., \& Tanaem, P. F. (2018). EVALUASI KINERJA SISTEM INFORMASI CUTI ELEKTRONIK ( SiCute ) MENGGUNAKAN FRAMEWORK COBIT 5 PADA BADAN KEPEGAWAIAN ,. SEBATIK, 367373. Jaka: Universitas Esa Unggul.

Fonna, N. (2019). Pengembangan Revolusi Industri 4.0 dalam Berbagai Bidang. GUEPEDIA.

Ghufron, M. A. (2018). Revolusi industri 4.0: Tantangan, Peluang dan Solusi Bagi Dunia Pendidikan. Seminar Nasional Dan Diskusi Panel Multidisiplin Hasil Penelitian Dan Pengabdian Kepada Masyarakat, 332-337.

Ibrahim, I., \& Nurpulaela, L. (2018). Evaluasi Tingkat Kematangan IT Service Management dengan Menggunakan Kerangka Kerja COBIT 5 Perusahaan Perkebunan. Seminar Nasional Teknik Elektro 2018, 292-295. Malang.

Meutia, E. D. (2017). Dampak Sosial Internet of Things. Seminar Nasional Dan Expo Teknik Elektro, 102-106. Banda Aceh.

Moleong, L. J. (2017). Metode Penelitian Kualitatif, cetakan ke-36, Bandung: PT. In Remaja Rosdakarya Offset.

Mukodi, M. (2019). PERANAN DEWAN PENDIDIKAN DALAM PENGEMBANGAN PENDIDIKAN DI KABUPATEN PACITAN DI ERA REVOLUSI INDUSTRI 4.0. Jurnal Penelitian Pendidikan, 11(1), 1555-1614.

Prasetyo, H., \& Sutopo, W. (2018). Industri 4.0: Telaah Klasifikasi Aspek Dan Arah Perkembangan Riset. J@ti Undip: Jurnal Teknik Industri, 13(1), 17. https://doi.org/10.14710/jati.13.1.17-26

Puspitasari, I. N. N. (2018). Pendidikan Pragmatis-Progresif Islamic International School (IIS) Kediri di Era Industri 4.0. Realita, 16(2), 115-128.

Rahadian, A. . (2019). REVITALISASI BIROKRASI MELALUI TRANSFORMASI BIROKRASI MENUJU E-GOVERNANCE PADA ERA REVOLUSI INDUSTRI 4.0. Prosiding Seminar Stiami, 4(1), 5-10.

Saggaf, S., Said, M. M., \& Saggaf, W. S. (2018). Reformasi Pelayanan Publik di Negara Berkembang (1st ed.). Makassar: SAH MEDIA.

Savitri, A. (2019). Revolusi Industri 4.0: Mengubah Tantangan Menjadi Peluang di Era Disrupsi 4.0. Jakarta: Badan Litbangkes - Kementerian Kesehatan RI.

Sawitri, D. (2019). Jurnal Ilmiah Maksitek ISSN : 2548-429X. JURNAL ILMIAH MAKSITEK, 3(November), 15-27. 
Sulistyanto, M. P. T., Nugraha, D. A., Sari, N., Karima, N., \& Asrori, W. (2015). Implementasi IoT (Internet of Things) dalam pembelajaran di Universitas Kanjuruhan Malang. SMARTICS Journal, 1(1), 20-23. Retrieved from http://ejournal.unikama.ac.id/index.php/jst/article/view/842

Umar, R., Riadi, I., \& Handoyo, E. (2019). Analisis Keamanan Sistem Informasi Berdasarkan Framework COBIT 5 Menggunakan Capability Maturity Model Integration (CMMI). Jurnal Sistem Informasi Bisnis, 9(1), 47. https://doi.org/10.21456/vol9iss1pp47-54 